\title{
The Association Between Diurnal Temperature Range and Clinic Visits for Upper Respiratory Tract Infection Among College Students in Wuhan, China
}

Faxue Zhang

Wuhan University

Chuangxin Wu

Wuhan University

Miaoxuan Zhang

Wuhan University

Han Zhang

Wuhan University

Huan Feng

Wuhan University

Wei Zhu ( $\nabla$ weizhu@whu.edu.cn )

Wuhan University

\section{Research Article}

Keywords: Diurnal temperature range, generalized additive model, upper respiratory tract infection, Outpatient visits

Posted Date: May 24th, 2021

DOl: https://doi.org/10.21203/rs.3.rs-483728/v1

License: (9) This work is licensed under a Creative Commons Attribution 4.0 International License.

Read Full License

Version of Record: A version of this preprint was published at Environmental Science and Pollution Research on August 7th, 2021. See the published version at https://doi.org/10.1007/s11356-021-157773. 


\section{Abstract}

The effects of daily mean temperature on health outcomes have been discussed in many previous studies, but few have considered the adverse impacts due to variance of temperature in one day. Diurnal temperature range (DTR) was a novel indicator calculated as maximum temperature minus minimum temperature in the same day. In this study, generalized additive model (GAM) with quasi-Poisson distribution was used to investigate the association between DTR and the number of daily outpatient visits for upper respiratory tract infection (URTI) among college students. Data about meteorological factors and air pollutants were provided by Hubei Meteorological Bureau and Wuhan Environmental Protection Bureau, respectively. Outpatient visits data were provided by the Hospital of Wuhan University from January 1, 2016 to November 31, 2018. Short-term exposure to DTR was associated with the increased risk of outpatient for URTI among all college students. Per $1{ }^{\circ} \mathrm{C}$ increased in DTR was associated with $0.89 \%(95 \% \mathrm{Cl}: 0.40,1.38)$ increased in outpatient visits of all college students for URTI at lag 0 day. The greatest effect values were observed in males [1.83\% $(95 \% \mathrm{Cl}: 0.81,2.86)]$, and in females [1.44\% (95\% Cl: $0.51,2.38)]$ at lag $0-6$ days. DTR had more adverse health impact in the warm season than that in the cold season. Public health departments should consider the negative effect of DTR to formulate more effective preventive and control measures for protecting vulnerable people.

\section{Introduction}

Upper respiratory tract infection (URTI) is a common disease among people, with respiratory symptoms including cough, stuffy nose, sniffling and sore throat, etc. According to the Global Burden of Disease Study 2016 (GBD 2016), the incidence of URTI is the highest among 318 diseases, even higher than dental caries and diarrhea (Disease, Injury, and Prevalence 2017). A previous study found that in Italy URTI accounted for about four-fifths of the outpatients for respiratory diseases in emergency department visits in people aged 0-18 years (Bono et al. 2016). Cross-sectional studies pointed out that URTI took up $30.1 \%$ of respiratory disorders and $26.4 \%$ of all hospital outpatient cases in Hong Kong (Lo et al. 2011; Nelson et al. 2007). Although the mortality caused by URTI was relatively low, it would have negative impacts on daily life, resulting in days lost from work and school (Mourtzoukou and Falagas 2007).

Climate change was generally agreed as one of the most important threats to human health in the twenty-first century, and can affect the health of the whole people in different ways (Watts et al. 2021; Tjaden et al. 2018; Fujimori et al. 2019). The high cost of human life and suffering caused by climate change will significantly affect economic output, with more than 302 billion potential labor hours lost in 2019. India and Indonesia were the most affected countries, and the economic impact of their lost potential labor hours was equivalent to $4-6 \%$ of their annual gross domestic product (GDP). In 2018 , the monetization cost of heat-related deaths in Europe was equivalent to $1.2 \%$ of the region's gross national income, which corresponded to the sum of the average annual income of 11 million European citizens (Cai et al. 2021). 
Ambient temperature was widely used to investigate the associations with the mortality and admission rate of respiratory disease in epidemical researches for the past few years (Zhao et al. 2019; Yang et al. 2018; Michelozzi et al. 2009). A study in Iran found that the mortality rate increased as the daily mean temperature decreased (Khanjani and Bahrampour 2013). Some researchers observed that optimal daily mean temperatures were existing $\left(18.1^{\circ} \mathrm{C}\right.$ for Wuhan, $19.0^{\circ} \mathrm{C}$ for London, and $29^{\circ} \mathrm{C}$ for Taiwan), which harmful effects were the lowest at these temperatures (Zhang et al. 2016; Patz et al. 2005; Hajat et al. 2002). However, most of them chose daily mean temperature as personal exposure index, which would ignore the variance of temperature within one day. Extreme temperature was confirmed to be associated with adverse health outcomes in a large number of epidemiological studies (Moghadamnia et al. 2017; Wang et al. 2017; Wu et al. 2016; Zhang, Yu, and Wang 2017). Heatwaves can break the human defense system and cause excessive death, especially in the elderly (Sun et al. 2014). The heatwave hit in Europe in 2003 caused about 15,000 and 3,100 excess deaths in France and Italy, respectively (Conti et al. 2007; Fouillet et al. 2006). Diurnal temperature range (DTR) was a novel index calculated as maximum temperature minus minimum temperature in the same day, to estimate the effects of many adverse outcomes. DTR can provide more information due to the consideration of the highest temperature and the lowest temperature (Braganza, Karoly, and Arblaster 2004). Byun et al. found that a $1{ }^{\circ} \mathrm{C}$ increased in DTR corresponded to $8.81 \%$ (95\% Cl: $3.46 \%-14.44 \%$ ) increase in emergency department visits for multiple sclerosis at lag 0-1 days (Byun et al. 2020). Wang et al. observed the acute effect of DTR on respiratory and digestive emergency room admissions among the elderly in Beijing [per $1{ }^{\circ} \mathrm{C}$ increased in DTR associated with $2.08 \%$ (95\% Cl: $0.88-3.29 \%)$ and $2.14 \%$ (95\% Cl: $0.71-3.59 \%)$ changed in relative risk at lag 0-7 days, respectively] (Wang et al. 2013).

Due to the influence of geographical environment and socio-economic factors, the health risks of climate change show obvious differences on the spatial and temporal scales (Gasparrini et al. 2017; Li et al. 2019; Messina et al. 2019; Barreca and Schaller 2020). Additionally, few studies focused on the relationship between DTR and the outpatient visits of URTI in college students. Therefore, it was necessary to carry out relevant researches in places with different weather patterns and different populations.

In this study, we collected the data about outpatient visits from the Hospital of Wuhan University and environmental factors from January 1, 2016 to November 31, 2018, and used generalized additive model with quasi-Poisson distribution to estimate the associations between short-term exposure to DTR and the risk of UTRI. A deep understanding of the relationship between DTR and URTI will help the relevant authorities to take appropriate measures to control the occurrence of the disease.

\section{Materials And Methods \\ 2.1 Study area}

In the current study, our study area is Wuhan University, located in the Wuchang district of Wuhan, the capital of Hubei Province. Wuhan is situated in the central part of China and the Yangtze River which has 
a typical subtropical monsoon climate with high temperatures in summer and low temperatures in winter. Hospital of Wuhan University is a university-level hospital affiliated with Wuhan University, consisting of four branches located in each of the four academic departments (Faculty of Medicine, Faculty of Engineering, Faculty of Arts and Sciences, and Faculty of Information Science). As the nearest and designated hospital for university students' medical insurance, which is the first choice for nearly 60,000 college students of Wuhan University to seek medical support and public health services.

\subsection{Data collection}

The data about outpatient visits were provided by the Hospital of Wuhan University from January 1, 2016 to November 31,2018. The medical information data included date of visit, gender, age, occupation and diagnosis. We extracted the part of college students according to their occupation (only students) and diagnosis (only UTRI). Finally, we established a new database to record the number of daily outpatient visits in college students for URTI.

Data about meteorological factors in this study period were provided by Hubei Meteorological Bureau (http://hb.cma.gov.cn/), including daily maximum, mean, and minimum temperature as well as relative humidity. Diurnal temperature range (DTR) was defined as maximum temperature minus minimum temperature in the same day. Data about air pollution including daily average concentration of fine particulate matter $\left(\mathrm{PM}_{2.5}\right)$, particulate matter $\left(\mathrm{PM}_{10}\right)$, sulfur dioxide $\left(\mathrm{SO}_{2}\right)$, nitrogen dioxide $\left(\mathrm{NO}_{2}\right)$ and ozone $\left(\mathrm{O}_{3}\right)$ were collective from Wuhan Environmental Protection Bureau (http://hbj.wuhan.gov.cn/), which had 10 monitoring stations distributed throughout the Wuhan city. Based on the geographical location of the study area, we chose the average values of these two nearest sites called Liyuan-Donghu and Ziyang-Wuchang as exposure indicators for the college students of Wuhan University.

\subsection{Statistical analysis}

Statistical description analysis (mean, standard deviation and quartiles) was used to exhibit the daily number of outpatient visits, meteorological factors and air pollution. Spearman rank correlation analysis was conducted to explore the relationships between paired data of air pollutants and meteorological factors. The generalized additive model (GAM) with quasi-Poisson distribution was used to estimate the increased number of outpatient visits of college students for URTI due to DTR. Cubic smoothing functions were applied to control multi-annual and seasonal trends in time-series design, as well as the weather factors (i.e., daily mean air temperature and relative humidity). Degree of freedom (df) was selected by referring to Akaike Information Criterion (AIC) and previous studies. Indicators for the day of week (DOW), the public holidays (holiday), the summer and winter vacation (vacation) were also adjusted as dummy variables in the GAM model.

The naturally smooth functions of two variables, average temperature and relative humidity, were included in the model to control the confounding effects of meteorological factors on the association between DTR and outpatient visits for URTI. The model was as follows: 


\section{$\lg \mathrm{E}(\mathrm{Yt})=\alpha+\beta Z t+D O W+n s($ time,$d f)+n s($ temperature,$d f)+n s($ humidity,$d f)$}

\section{+ Public Holiday + Vacation (1)}

Where $\mathrm{E}(Y t)$ is the estimated daily outpatient visits of college students for URTI; $\mathrm{a}$ is the intercept of the model; $\beta$ is the log of excess relative risk in upper respiratory clinic visits corresponding to each $1{ }^{\circ} \mathrm{C}$ increase in DTR; Zt represents the values of DTR on day $t,{ }^{\circ} \mathrm{C}$; ns is a spline smoothing function for the nonlinear variables such as time, temperature and humidity; $\mathrm{df}$ means the degree of freedom; In the final model, we defined 7 df per year for time trends[29-31], 6 and 3 df per year for daily mean temperature and relative humidity, respectively[30, 32].

DTR was incorporated into the model to evaluate the relationship between the outpatient visits for URTI and DTR. Due to the potential delayed effects of DTR on the outpatient visits for URTI, this study used the single-day lags ( $\operatorname{lag} 0, \operatorname{lag} 1, \operatorname{lag} 2$, $\operatorname{lag} 3$, $\operatorname{lag} 4$, lag $5, \operatorname{lag} 6$, and $\operatorname{lag} 7$ day) and cumulative lags (lag $0-1$, lag $0-2$, lag $0-3$, lag $0-4$, lag $0-5$, lag $0-6$ and lag $0-7$ days) to estimate the effects of DTR at different lag days. We also analyzed the association between DTR and outpatient visits for URTI in different gender (males and females) and season [warm (form April to October) and cold (from November to March of next year)] groups. After evaluating the health effects of DTR in the initial model, two sensitivity analyses were conducted to assess the robustness of effects of DTR on outpatient visits for URTI. One was constructing new models by adding each air pollutant into models (only one air pollutant at a time), another was changing the dfs for time (from 7 to 6 or 8 per year) to examine the robustness of the results in our study.

Consistent with previous studies, results in this study were reported as excess relative risk (ERR: RR-1) and $95 \%$ confidence intervals $(C l)$. All statistical analyses were conducted in R software (version 4.0.3). Results with a 2 -sided and $p$ value $<0.05$ were statistically significant.

\section{Results}

Figure 1 illustrates the distribution of daily diurnal temperature range (DTR) and the number of outpatient visits for URTI stratified by gender in the Hospital of Wuhan University, China. Similar trends between outpatient visits and DTR were observed. Relatively higher values for outpatient visits and DTR were found in cold seasons. Due to most of college students leaving university during the winter vacation, in particular, Chinese New Year (Usually occurred in January or February), the number of outpatient visits was extremely low even though DTR remained high level.

Table 1 shows the basic descriptions of demographics and environmental factors (meteorological factors and air pollution). There were 44, 449 outpatient visits for URTI were recorded in hospital of Wuhan University from January 1, 2016 to December 31, 2018, included 23,654 females (53.2\%) and 20,845 males (46.8\%). Daily mean outpatient visits in this study period were about 41, 19 and 22 for all, males and females, respectively. For meteorological factors, the minimum, mean, and maximum DTR were 0.9 
${ }^{\circ} \mathrm{C}, 8.8^{\circ} \mathrm{C}$, and $20.5^{\circ} \mathrm{C}$. Daily mean temperature and relative humidity were $8.8{ }^{\circ} \mathrm{C}$ and $79.5 \%$, respectively. For air pollution, the daily average concentrations of $\mathrm{PM}_{2.5}, \mathrm{PM}_{10}, \mathrm{SO}_{2}, \mathrm{NO}_{2}$ and $\mathrm{O}_{3}$ were 50.6 $\mathrm{ug} / \mathrm{m}^{3}, 80.1 \mathrm{ug} / \mathrm{m}^{3}, 10.8 \mathrm{ug} / \mathrm{m}^{3}, 44.3 \mathrm{ug} / \mathrm{m}^{3}$, and $88.0 \mathrm{ug} / \mathrm{m}^{3}$, separately. As seen in Figure 2, DTR were negatively correlated with meteorological factors and positively correlated with air pollutants. The largest values of spearman correlation coefficient about DTR were found between DTR and PM $\mathrm{PM}_{10}(r=0.53$, $P<0.001)$, and an extremely weak correlation was observed between DTR and temperature $(r=-0.01$, $\mathrm{P}<0.001)$, as seen in Table $\mathrm{S} 1$.

\section{Table 1}

The descriptions of daily clinic visits of college students for URTI and environmental factors.

\begin{tabular}{|c|c|c|c|c|c|c|c|c|}
\hline & \multirow[t]{2}{*}{ Clinic visits (\%) } & \multicolumn{7}{|c|}{ 24-hour average } \\
\hline & & Min & $\mathrm{P}_{25}$ & $\mathrm{P}_{50}$ & $\mathrm{P}_{75}$ & Max & Mean & SD \\
\hline All & 44499 (100.0\%) & 0.0 & 20.0 & 37.0 & 60.0 & 122.0 & 40.6 & 24.6 \\
\hline \multicolumn{9}{|l|}{ Gender } \\
\hline Male & 20845 (46.8\%) & 0.0 & 9.0 & 17.0 & 28.0 & 58.0 & 19.0 & 12.4 \\
\hline Female & $23654(53.2 \%)$ & 0.0 & 11.0 & 20.0 & 30.0 & 64.0 & 21.6 & 12.9 \\
\hline \multicolumn{9}{|l|}{ Meteorological factors } \\
\hline Mean temperature $\left({ }^{\circ} \mathrm{C}\right)$ & - & -3.8 & 9.3 & 18.0 & 25.4 & 33.9 & 17.3 & 9.4 \\
\hline Max temperature $\left({ }^{\circ} \mathrm{C}\right)$ & - & -2.0 & 14.6 & 23.2 & 30.3 & 39.7 & 22.2 & 9.5 \\
\hline Min temperature $\left({ }^{\circ} \mathrm{C}\right)$ & - & -9.4 & 5.4 & 14.1 & 21.6 & 29.6 & 13.4 & 9.5 \\
\hline $\operatorname{DTR}\left({ }^{\circ} \mathrm{C}\right)$ & - & 0.9 & 5.5 & 8.7 & 11.8 & 20.5 & 8.8 & 4.2 \\
\hline Relative humidity (\%) & - & 41.0 & 72.0 & 80.0 & 87.0 & 100.0 & 79.5 & 10.6 \\
\hline \multicolumn{9}{|l|}{ Air pollutants } \\
\hline $\mathrm{PM}_{2.5}\left(\mathrm{ug} / \mathrm{m}^{3}\right)$ & - & 3.9 & 27.0 & 41.4 & 65.4 & 227.0 & 50.6 & 33.8 \\
\hline $\mathrm{PM}_{10}\left(\mathrm{ug} / \mathrm{m}^{3}\right)$ & - & 5.0 & 46.5 & 74.0 & 103.5 & 600.0 & 80.1 & 47.1 \\
\hline $\mathrm{SO}_{2}\left(\mathrm{ug} / \mathrm{m}^{3}\right)$ & - & 1.5 & 6.0 & 9.5 & 14.3 & 52.0 & 10.8 & 6.5 \\
\hline $\mathrm{NO}_{2}\left(\mathrm{ug} / \mathrm{m}^{3}\right)$ & - & 9.6 & 29.6 & 40.8 & 56.8 & 115.0 & 44.3 & 19.3 \\
\hline $\mathrm{O}_{3}\left(\mathrm{ug} / \mathrm{m}^{3}\right)$ & - & 6.0 & 51.0 & 81.0 & 121.0 & 248.5 & 88.0 & 46.6 \\
\hline
\end{tabular}


Figure 3 reveals the exposure-response (E-R) curves between DTR and outpatient visits for UTRI stratified by gender at lag 0-6 days. Although there were small plateau periods in the middle of the curves, nearly similar linear upward trends were found in all, males and females, which indicated that DTR was a risk factor for the increased in the number of outpatient visits for URTI.

Table 2 shows the estimated effects with $95 \% \mathrm{Cl}$ in outpatient visits of college students for URTI associated with per $1^{\circ} \mathrm{C}$ increase in DTR at different lag days. The largest effect values were found at lag 0 day in single lags. A $1{ }^{\circ} \mathrm{C}$ increased in DTR was associated with $0.89 \%(95 \% \mathrm{Cl}: 0.40,1.38)$ increased in outpatient visits of college students for URTI in all, $0.76 \%(95 \% \mathrm{Cl}: 0.18,1.34)$ in males and $1.01 \%(95 \% \mathrm{Cl}$ : $0.48,1.54)$ in females. The estimates with statistically significant were detected in all cumulative lags, and the greatest effect values were observed in all [1.62\% $(95 \% \mathrm{Cl}: 0.76,2.50)]$, in males [1.83\% $(95 \% \mathrm{Cl}$ : $0.81,2.86)]$, and in females [1.44\% (95\%Cl: $0.51,2.38)]$ at lag $0-6$ days. No matter at single-day lags or cumulative lags, it was worth noting that the effects of DTR in males were higher than females at longer lag days. 
Table.2

The estimated effects with $95 \% \mathrm{Cl}$ in clinic visits of college students for URTI associated with per $1{ }^{\circ} \mathrm{C}$ increase in DTR at different lag days.

\begin{tabular}{|llll}
\hline Lag days & ALL & Males & Females \\
\hline Single lags & & & \\
\hline lag0 & $\mathbf{0 . 8 9 ( 0 . 4 0 , 1 . 3 8 )}$ & $\mathbf{0 . 7 6}(\mathbf{0 . 1 8 , 1 . 3 4 )}$ & $\mathbf{1 . 0 1}(\mathbf{0 . 4 8 , 1 . 5 4 )}$ \\
\hline lag1 & $0.44(-0.03,0.92)$ & $0.29(-0.27,0.86)$ & $\mathbf{0 . 5 7}(\mathbf{0 . 0 6 , 1 . 0 9 )}$ \\
\hline lag2 & $0.32(-0.13,0.78)$ & $0.40(-0.13,0.94)$ & $0.26(-0.23,0.74)$ \\
\hline lag3 & $0.38(-0.05,0.81)$ & $\mathbf{0 . 5 2}(\mathbf{0 . 0 1 , 1 . 0 3 )}$ & $0.25(-0.21,0.71)$ \\
\hline lag4 & $\mathbf{0 . 5 3 ( 0 . 1 1 , 0 . 9 5 )}$ & $\mathbf{0 . 6 7}(\mathbf{0 . 1 7}, 1.17)$ & $0.41(-0.04,0.86)$ \\
\hline lag5 & $0.41(-0.01,0.82)$ & $\mathbf{0 . 5 4}(\mathbf{0 . 0 6 , 1 . 0 3 )}$ & $0.28(-0.17,0.72)$ \\
\hline lag6 & $0.23(-0.18,0.64)$ & $0.26(-0.22,0.75)$ & $0.20(-0.24,0.64)$ \\
\hline lag7 & $0.04(-0.37,0.45)$ & $0.09(-0.39,0.57)$ & $-0.01(-0.45,0.43)$
\end{tabular}

Cumulative lags

\begin{tabular}{llll} 
lag01 & $0.96(0.38,1.55)$ & $0.76(0.07,1.46)$ & $1.14(0.52,1.77)$ \\
\hline lag02 & $1.05(0.40,1.71)$ & $0.97(0.19,1.75)$ & $1.14(0.43,1.84)$ \\
\hline lag03 & $1.14(0.43,1.86)$ & $1.17(0.32,2.02)$ & $1.12(0.35,1.90)$ \\
\hline lag04 & $1.39(0.62,2.16)$ & $1.51(0.60,2.44)$ & $1.28(0.45,2.11)$ \\
\hline lag05 & $1.58(0.76,2.40)$ & $1.79(0.82,2.77)$ & $1.39(0.51,2.28)$ \\
\hline lag06 & $1.62(0.76,2.50)$ & $1.83(0.81,2.86)$ & $1.44(0.51,2.38)$ \\
\hline lag07 & $1.57(0.66,2.49)$ & $1.80(0.73,2.89)$ & $1.37(0.39,2.36)$
\end{tabular}

Note: Bold results are statistically significant $(p<0.05)$

Figure 4 reveals the percent changes and $95 \% \mathrm{Cl}$ for URTI outpatient visits of college students associated with per $1^{\circ} \mathrm{C}$ increase in DTR stratified by season at different lag days. The effects of cold season which larger than warm season were only observed (but without statistically significant) in all at lag 1 and 6 days, in males at lag 0, 3, 5 and 0-1 days, and in females at lag 1, 2 and 6 days. However, the relatively higher estimates were mainly found in warm season especially at cumulative lags. For example, per $1^{\circ} \mathrm{C}$ increase in DTR corresponded to $2.13 \%(95 \% \mathrm{Cl}$ : $0.72,3.57)$ increased in the number of outpatient visits for URTI in all, $2.10 \%(95 \% \mathrm{Cl}: 0.33,3.90)$ in males and $2.16 \%(95 \% \mathrm{Cl}: 0.60,3.75)$ in females at lag $0-7$ days. As seen in Table S2, the effect values of females were larger than males at all cumulative lags in warm season but males [1.50\% (95\% Cl: $0.10,2.92)]$ were higher than females [1.31\% $(95 \% \mathrm{Cl}: 0.05,2.59)]$ at lag 0-6 days in cold season. 
Table 3 shows the percent changes and $95 \% \mathrm{Cl}$ for URTI outpatient visits of college students associated with a $1^{\circ} \mathrm{C}$ increase in DTR at lag 0-6 days in sensitivity analysis. Although the effect values were decreased to varying degrees compared with the unadjusted models when adding each air pollutants one by one, the vast majority of effect values remained statistically significant. After changing the degree of freedom of time from 7 to 6 or 8 , all the effect values also remained statistically significant. The above tests illustrated the robustness of our model and results.

\begin{tabular}{|c|c|c|c|}
\hline \multicolumn{4}{|c|}{ Table.3 } \\
\hline \multicolumn{4}{|c|}{$\begin{array}{l}\text { Percent changes and } 95 \% \mathrm{Cl} \text { for URTI clinic visits of college students associated with a } 1^{\circ} \mathrm{C} \text { increase } \\
\text { in DTR at lag } 06 \text { day in sensitivity analysis. }\end{array}$} \\
\hline Parameter & All & Male & Female \\
\hline \multicolumn{4}{|c|}{ +Air pollutants } \\
\hline +PM2.5 & $1.53(0.66,2.40)$ & $1.73(0.70,2.77)$ & $1.35(0.41,2.29)$ \\
\hline +PM10 & $1.37(0.49,2.26)$ & $1.51(0.47,2.56)$ & $1.24(0.29,2.19)$ \\
\hline +SO2 & $1.29(0.38,2.22)$ & $1.53(0.45,2.63)$ & $1.08(0.09,2.07)$ \\
\hline +NO2 & $1.08(0.18,1.99)$ & $1.32(0.25,2.40)$ & $0.86(-0.11,1.84)$ \\
\hline+03 & $1.31(0.42,2.20)$ & $1.44(0.39,2.50)$ & $1.19(0.23,2.15)$ \\
\hline \multicolumn{4}{|c|}{ Degree of freedom } \\
\hline$d f=6$ & $1.89(1.02,2.77)$ & $2.07(1.04,3.10)$ & $1.73(0.79,2.67)$ \\
\hline$d f=8$ & $1.70(0.82,2.58)$ & $1.81(0.77,2.85)$ & $1.60(0.66,2.55)$ \\
\hline
\end{tabular}

\section{Discussion}

In the current study, GAM was used to investigate the link of short-term exposure to DTR and the daily number of outpatient visits of college students for URTI at Hospital of Wuhan University in Wuhan, China. After adjusting for multiple covariates in this model, we noticed that with the increase of DTR, the number of outpatients was increasing accordingly. We also found the strongest effects occurred at lag 0 day in single lags and lag 0-6 days at cumulative lags whatever for all, males and females. Females were more vulnerable to extremely acute exposure to DTR than males. In generally, the estimates of the associations between DTR and URTI were larger in warm season than cold season, especially in the cumulative lags. This study might have great significance to the prevention of upper respiratory tract infection in college students and provide scientific epidemiological evidence and reference for relevant administration department to take measures to control temperature change. 
Our results showed that per $1^{\circ} \mathrm{C}$ increased in DTR would elevate $0.89 \%$ (95\% $\left.\mathrm{Cl}: 0.40,1.38\right)$ and $1.62 \%$ $(95 \% \mathrm{Cl}: 0.76,2.50)$ in the daily number of outpatient visits of all college students for URTI at lag 0 and 0 6 days, respectively. These findings were consistent with some previous studies (Ma et al. 2018; Phosri, Sihabut, and Jaikanlaya 2020). For instant, Ge et al. found per $1{ }^{\circ} \mathrm{C}$ increment of DTR could increase $0.94 \%(95 \%$ Cl: $0.34,1.55)$ and $1.60 \%(95 \%$ Cl: 0.62, 2.58) in Emergency-room Visits for respiratory tract infection in Shanghai at lag 0 day and at lag 0-5 days, separately (Ge et al. 2013). Li et al. observed that a $1{ }^{\circ} \mathrm{C}$ increase in DTR corresponded to $2.55 \%(95 \% \mathrm{Cl}: 1.97,4.01)$ increase in the number of daily Emergency-room Visits for respiratory tract infection in children aged $\leq 5$ years old at lag 1 day (Li, Yang, and Wang 2014).

A tremendous amount of previous studies pointed out that DTR might be an independent risk factor for human health (Kim et al. 2016; Ding et al. 2015). The potential mechanism of action of DTR was not well understood yet, but one research had been suggested that rapid changes in temperature can increase respiratory load and thus induce respiratory health events (Imai et al. 1998). Air with suddenly altered temperature was inhaled into the human body related to up-regulate the release of mast cell-associated inflammatory mediators (Togias et al. 1985). In addition, the rapid decrease of temperature in respiratory epithelial would lead to the decrease of the effectiveness of local respiratory defense (for example, mucociliary clearance and leukocyte phagocytosis) (Diesel, Lebel, and Tucker 1991; Bang 1961). DTR might be an additional independent environmental influence, and its variation can result in the increment of respiratory stress (Ge et al. 2013). The high value of DTR can promote the spread and reproduction of bacteria and viruses (Cheng et al. 2014; Onozuka 2015). Besides, when the temperature of respiratory epithelial fluctuated violently, it might affect the host defense function of the respiratory system, nasal response and airway mucosal cilia clearance, thus increasing the incidence of respiratory infections (Graudenz et al. 2006; Diesel, Lebel, and Tucker 1991). Based on the complexity and diversity of DTR impacts, we called for more researches to explore its exact mechanism.

It was worth noting that in our results the effect values of per $1{ }^{\circ} \mathrm{C}$ increment of DTR in females [0.76\%, 95\%Cl: $(0.18,1.34)]$ for URTI at current day was higher than males [1.01\%, 95\% Cl: $(0.48,1.54)]$. However, in a longer lag period, the males emerged greater effect values than females.

For instant, a $1{ }^{\circ} \mathrm{C}$ increased in DTR associated with $1.83 \%(95 \% \mathrm{Cl}: 0.81,2.86)$ elevated in the daily number of outpatient visits of male college students for URTI, but only $1.44 \%(95 \% \mathrm{Cl}: 0.51,2.38)$ in female college students. One study observed the relative risks of DTR and hospital admission for cardiovascular in males from lower than females at lag 0 day $[1.044(0.991,1.101)$ for males vs 1.058 $(1.004,1.116)$ for females] to higher than females at lag $0-7$ days $[1.151(1.022,1.296)$ vs $1.115(0.988$, 1.257)], which were similar to our results (Phosri, Sihabut, and Jaikanlaya 2020). Nevertheless, researchers also found females were more likely to be vulnerable to DTR than males at all lag days (Zhang, Yu, Yang, et al. 2017; Zhou et al. 2014). The possible reason for such inconsistent results was that the study area (climate conditions) and population (economy and education) were different (Basu 2009; Ding et al. 2015). 
Among all the results with statistically significant in this study, we observed that the effect values in the warm season were higher than those in the cold season. Some previous studies found similar outcomes (Zhang, Yu, Bao, et al. 2017; Zheng et al. 2016). A positive and stronger relationship was revealed between DTR and childhood asthma exacerbations in the warm season (May to September) (Hu et al. 2020). However, researchers in Shanghai pointed out results which were inconsistent with our study, they only found the associations of DTR and respiratory mortality in the cold season (Kan et al. 2007). In addition, a study in Changchun found that for a $1{ }^{\circ} \mathrm{C}$ increased in DTR increased the risk of hospital admissions for COPD by $11.5 \%$ (95\% Cl: $10.0,12.9)$ in the cold season, which was higher than $9.0 \%$ $(95 \% \mathrm{Cl}: 7.7,10.3)$ in the warm season (Ma et al. 2018). The results that appeared in the current study can be partially explained as follows: Due to the relationship dictated by the frequency of cooler air masses in the warm season, these days with lower minimum temperatures usually had higher maximum temperatures, which led to the values of DTR were higher than that in the cold season (Davis, Hondula, and Sharif 2020).

In sensitivity analysis, the associations of DTR and the daily outpatient visits of all college students for URTI remained statistically significant despite the effect values were slightly reduced after adjusting for air pollutants (e.g. $\mathrm{PM}_{2.5}, \mathrm{PM}_{10}, \mathrm{SO}_{2}, \mathrm{NO}_{2}$, and $\mathrm{O}_{3}$ ). Similar results were also found in male and female college students, which meant DTR was a robust and trustworthy predictor for outpatient visits of college students for URTI. Many previous studies pointed out that DTR was still associated with mortalities and emergency room admissions for a variety of cardiovascular and respiratory diseases when adding air pollutants to model (Liang, Liu, and Kuo 2009; Yang et al. 2013; Tam et al. 2009), which were consistent with our findings.

In this study, the exposure-response curves between DTR and the daily outpatient visits of URTI in all, male and female college students were close to linear upward trends at lag 0-6 days. These linear-like trends were also found in previous studies (Wang et al. 2020; Zheng et al. 2016). Therefore, the generalized additive models were used by us to investigate the associations of DTR and the outpatient visits for URTI. However, in some other studies, U- or J-shaped exposure-response curves between DTR and the occurrence of adverse outcomes were revealed (Deng et al. 2020; Hu et al. 2018; Zhao et al. 2017). A study conducted in Hefei even showed slightly M-shaped exposure-response curve between DTR and the risk of admissions for tuberculosis (Huang et al. 2020). The reasons for such inconsistent results might be that the types of population and disease in these studies were very different.

The strongest effect values of DTR were found at the current day in the models of single-day lags, whether for male, female, or all college students. Likewise, a time-series study in Beijing indicated that the adverse effects of DTR peaked at lag 0 day [per $1{ }^{\circ} \mathrm{C}$ increased in DTR corresponded to $0.58 \%$ $(95 \% \mathrm{Cl}: 0.02,1.15)$ increase in emergency room admissions for respiratory disease] (Wang et al. 2013). A study conducted in Changchun, one northeast city of China, reported that the largest relative risk of 1.023 $(95 \% \mathrm{Cl}: 1.004,1.042)$ about hospital admissions for chronic obstructive pulmonary disease was observed at lag 7 day in the males when $1^{\circ} \mathrm{C}$ increased in DTR (Ma et al. 2018), which was inconsistent with our results. 
In summary, our study has several advantages: 1) According to the information I have, this is the first study exploring the associations between DTR and upper respiratory tract infection among college students in China. 2) University is one of the most important stages of learning. College students with upper respiratory tract infection will seriously affect the efficiency of learning. Therefore, it is necessary to investigate the relationship between DTR and upper respiratory tract infection. 3) The population of this study all live in Wuhan University, an area of about 3.5 square kilometers, and they will stay in school most of the year because of their studies. So, it is reasonable to suppose that they have similar exposure backgrounds. 4) The hospital of Wuhan University had set up four branches in four academic departments to facilitate college students with different majors and faculties to seek basic medical treatment. In addition, benefit by the medical insurance policy of Wuhan University, the medical expenses of our college students in the Hospital of Wuhan University are all reduced $90 \%$, which greatly avoids the bias of not choosing to seek medical treatment due to the cost (Zhang et al. 2021), and makes the exposure-response relationship of DTR and the daily outpatient visits of URTI in this study more genuine and believable.

Nevertheless, there are several limitations of this study that must be mentioned: 1) data about meteorological factors and air pollutants were collected from monitoring stations with a certain distance from Wuhan University, and individuals' indoor and outdoor activity duration cannot be measured, which would inevitably lead to misclassification in exposure to DTR to a certain degree. 2) Due to the unavailability of data about more detailed personal information, for example, body mass index (BMI), eating habits, smoking status, history of diseases and so on, which would result in unavoidable errors. 3) The outpatient visit data provided from the hospital of Wuhan University do not contain patients' name because of medical ethics, therefore, we cannot distinguish the cases of repeated visits and regard each visit record as a new case. More comprehensive researches were warrant to reveal the associations between DTR and URTI.

\section{Conclusions}

In conclusion, we investigate the short-term effects of DTR on the daily number of outpatient visits in college students for URTI from 2016 to 2018 in Wuhan University, China. Results in this study show that short-term exposure to DTR was linked with the increased risk of outpatient for URTI among all college students at the Hospital of Wuhan University, which meant DTR was a novel indicator to estimate the relationship between environment and disease. Males were more susceptible to DTR than females in the longer lag days. DTR had more adverse health impact in the warm season than that in the cold season. Consequently, public health departments should consider not only the health impact of daily mean temperature, but also the DTR, to formulate better preventive measures.

\section{Declarations}

\section{Author Contributions}


Wei Zhu conceived and designed the study; Chuangxin Wu and Miaoxuan Zhang collected and cleaned the data; Faxue Zhang performed the data analysis and drafted the manuscript. Huan Feng and Han Zhang helped revise the manuscript. All authors read and approved the final manuscript.

\section{Ethical Approval}

This study was approved by the Ethics Committee of Wuhan University.

\section{Consent to Participate}

Not applicable.

\section{Consent to Publish}

Not applicable.

\section{Competing Interests}

The authors declare that they have no competing interests.

\section{Availability of data and materials}

Not applicable.

\section{Funding}

Not applicable.

\section{References}

1. Bang, F. B. 1961. 'Mucociliary function as protective mechanism in upper respiratory tract', Bacteriological reviews, 25: 228-36.

2. Barreca, A., and J. Schaller. 2020. 'The impact of high ambient temperatures on delivery timing and gestational lengths', Nature Climate Change, 10: 77-+.

3. Basu, R. 2009. 'High ambient temperature and mortality: a review of epidemiologic studies from 2001 to 2008', Environ Health, 8: 40.

4. Bono, R., V. Romanazzi, V. Bellisario, R. Tassinari, G. Trucco, A. Urbino, C. Cassardo, C. Siniscalco, P. Marchetti, and A. Marcon. 2016. 'Air pollution, aeroallergens and admissions to pediatric emergency 
room for respiratory reasons in Turin, northwestern Italy', BMC Public Health, 16: 722.

5. Braganza, K., D. J. Karoly, and J. M. Arblaster. 2004. 'Diurnal temperature range as an index of global climate change during the twentieth century', Geophysical Research Letters, 31.

6. Byun, S., W. Myung, H. Kim, and H. Lee. 2020. 'Association between diurnal temperature range and emergency department visits for multiple sclerosis: A time-stratified case-crossover study', Sci Total Environ, 720: 137565.

7. Cai, W., C. Zhang, H. P. Suen, S. Ai, Y. Bai, J. Bao, B. Chen, L. Cheng, X. Cui, H. Dai, Q. Di, W. Dong, D. Dou, W. Fan, X. Fan, T. Gao, Y. Geng, D. Guan, Y. Guo, Y. Hu, J. Hua, C. Huang, H. Huang, J. Huang, T. Jiang, K. Jiao, G. Kiesewetter, Z. Klimont, P. Lampard, C. Li, Q. Li, R. Li, T. Li, B. Lin, H. Lin, H. Liu, Q. Liu, X. Liu, Y. Liu, Z. Liu, Z. Liu, Z. Liu, S. Lou, C. Lu, Y. Luo, W. Ma, A. McGushin, Y. Niu, C. Ren, Z. Ren, Z. Ruan, W. Schopp, J. Su, Y. Tu, J. Wang, Q. Wang, Y. Wang, Y. Wang, N. Watts, C. Xiao, Y. Xie, H. Xiong, M. Xu, B. Xu, L. Xu, J. Yang, L. Yang, L. Yu, Y. Yue, S. Zhang, Z. Zhang, J. Zhao, L. Zhao, M. Zhao, Z. Zhao, J. Zhou, and P. Gong. 2021. 'The 2020 China report of the Lancet Countdown on health and climate change', Lancet Public Health, 6: e64-e81.

8. Cheng, J., Z. Xu, R. Zhu, X. Wang, L. Jin, J. Song, and H. Su. 2014. 'Impact of diurnal temperature range on human health: a systematic review', Int J Biometeorol, 58: 2011-24.

9. Conti, S., M. Masocco, P. Meli, G. Minelli, E. Palummeri, R. Solimini, V. Toccaceli, and M. Vichi. 2007. 'General and specific mortality among the elderly during the 2003 heat wave in Genoa (Italy)', Environmental Research, 103: 267-74.

10. Davis, R. E., D. M. Hondula, and H. Sharif. 2020. 'Examining the diurnal temperature range enigma: why is human health related to the daily change in temperature?', Int J Biometeorol, 64: 397-407.

11. Deng, J., X. Hu, C. Xiao, S. Xu, X. Gao, Y. Ma, J. Yang, M. Wu, X. Liu, J. Ni, and F. Pan. 2020. 'Ambient temperature and non-accidental mortality: a time series study', Environ Sci Pollut Res Int, 27: 419096.

12. Diesel, D. A., J. L. Lebel, and A. Tucker. 1991. 'Pulmonary Particle Deposition and Airway Mucociliary Clearance in Cold-Exposed Calves', American Journal of Veterinary Research, 52: 1665-71.

13. Ding, Z., P. Guo, F. Xie, H. Chu, K. Li, J. Pu, S. Pang, H. Dong, Y. Liu, F. Pi, and Q. Zhang. 2015. 'Impact of diurnal temperature range on mortality in a high plateau area in southwest China: A time series analysis', Sci Total Environ, 526: 358-65.

14. Disease, G. B. D., Incidence Injury, and Collaborators Prevalence. 2017. 'Global, regional, and national incidence, prevalence, and years lived with disability for 328 diseases and injuries for 195 countries, 1990-2016: a systematic analysis for the Global Burden of Disease Study 2016', Lancet, 390: 121159.

15. Fouillet, A., G. Rey, F. Laurent, G. Pavillon, S. Bellec, C. Guihenneuc-Jouyaux, J. Clavel, E. Jougla, and D. Hemon. 2006. 'Excess mortality related to the August 2003 heat wave in France', Int Arch Occup Environ Health, 80: 16-24.

16. Fujimori, S., T. Hasegawa, V. Krey, K. Riahi, C. Bertram, B. L. Bodirsky, V. Bosetti, J. Callen, J. Despres, J. Doelman, L. Drouer, J. Emmerling, S. Frank, O. Fricko, P. Havlik, F. Humpenoder, J. F. L. Koopman, H. 
van Meijl, Y. Ochi, A. Popp, A. Schmitz, K. Takahashi, and D. van Vuuren. 2019. 'A multi-model assessment of food security implications of climate change mitigation', Nature Sustainability, 2: 38696.

17. Gasparrini, A., Y. Guo, F. Sera, A. M. Vicedo-Cabrera, V. Huber, S. Tong, M. de Sousa Zanotti Stagliorio Coelho, P. H. Nascimento Saldiva, E. Lavigne, P. Matus Correa, N. Valdes Ortega, H. Kan, S. Osorio, J. Kysely, A. Urban, J. J. K. Jaakkola, N. R. I. Ryti, M. Pascal, P. G. Goodman, A. Zeka, P. Michelozzi, M. Scortichini, M. Hashizume, Y. Honda, M. Hurtado-Diaz, J. Cesar Cruz, X. Seposo, H. Kim, A. Tobias, C. Iniguez, B. Forsberg, D. O. Astrom, M. S. Ragettli, Y. L. Guo, C. F. Wu, A. Zanobetti, J. Schwartz, M. L. Bell, T. N. Dang, D. D. Van, C. Heaviside, S. Vardoulakis, S. Hajat, A. Haines, and B. Armstrong. 2017. 'Projections of temperature-related excess mortality under climate change scenarios', Lancet Planet Health, 1: e360-e67.

18. Ge, W. Z., F. Xu, Z. H. Zhao, J. Z. Zhao, and H. D. Kan. 2013. 'Association between diurnal temperature range and respiratory tract infections', Biomed Environ Sci, 26: 222-5.

19. Graudenz, G. S., R. G. Landgraf, S. Jancar, A. Tribess, S. G. Fonseca, K. C. Fae, and J. Kalil. 2006. 'The role of allergic rhinitis in nasal responses to sudden temperature changes', J Allergy Clin Immunol, 118: $1126-32$.

20. Hajat, S., R. S. Kovats, R. W. Atkinson, and A. Haines. 2002. 'Impact of hot temperatures on death in London: a time series approach', J Epidemiol Community Health, 56: 367-72.

21. Hu, W., Y. Li, W. Han, L. Xue, W. Zhang, W. Ma, and P. Bi. 2018. 'Meteorological factors and the incidence of mumps in Fujian Province, China, 2005-2013: Non-linear effects', Sci Total Environ, 619620: 1286-98.

22. Hu, Y., J. Cheng, F. Jiang, S. Liu, S. Li, J. Tan, Y. Yin, and S. Tong. 2020. 'Season-stratified effects of meteorological factors on childhood asthma in Shanghai, China', Environmental Research, 191: 110115.

23. Huang, K., X. J. Yang, C. Y. Hu, K. Ding, W. Jiang, X. G. Hua, J. Liu, J. Y. Cao, C. Y. Sun, T. Zhang, X. H. Kan, and X. J. Zhang. 2020. 'Short-term effect of ambient temperature change on the risk of tuberculosis admissions: Assessments of two exposure metrics', Environmental Research, 189: 109900.

24. Imai, Y., S. Nobuoka, J. Nagashima, T. Awaya, J. Aono, F. Miyake, and M. Murayma. 1998. 'Acute myocardial infarction induced by alternating exposure to heat in a sauna and rapid cooling in cold water', Cardiology, 90: 299-301.

25. Kan, H., S. J. London, H. Chen, G. Song, G. Chen, L. Jiang, N. Zhao, Y. Zhang, and B. Chen. 2007. 'Diurnal temperature range and daily mortality in Shanghai, China', Environmental Research, 103: 424-31.

26. Khanjani, N., and A. Bahrampour. 2013. 'Temperature and cardiovascular and respiratory mortality in desert climate. A case study of Kerman, Iran', Iranian J Environ Health Sci Eng, 10: 11.

27. Kim, J., J. Shin, Y. H. Lim, Y. Honda, M. Hashizume, Y. L. Guo, H. Kan, S. Yi, and H. Kim. 2016. 'Comprehensive approach to understand the association between diurnal temperature range and 
mortality in East Asia', Sci Total Environ, 539: 313-21.

28. Li, S., L. Gilbert, S. O. Vanwambeke, J. Yu, B. V. Purse, and P. A. Harrison. 2019. 'Lyme Disease Risks in Europe under Multiple Uncertain Drivers of Change', Environ Health Perspect, 127: 67010.

29. Li, T., Z. Yang, and M. Wang. 2014. 'Diurnal temperature range related to respiratory tract infection in childhood', Pediatr Infect Dis J, 33: 1309-10.

30. Liang, W. M., W. P. Liu, and H. W. Kuo. 2009. 'Diurnal temperature range and emergency room admissions for chronic obstructive pulmonary disease in Taiwan', Int J Biometeorol, 53: 17-23.

31. Lo, Y. Y., C. L. Lam, S. W. Mercer, D. Y. Fong, A. Lee, T. P. Lam, R. Lee, B. Chiu, J. Tang, B. Chui, D. Chao, A. Lam, and K. Chan. 2011. 'Patient morbidity and management patterns of community-based primary health care services in Hong Kong', Hong Kong Med J, 17: 33-7.

32. Ma, Y., Y. Zhao, J. Zhou, Y. Jiang, S. Yang, and Z. Yu. 2018. 'The relationship between diurnal temperature range and COPD hospital admissions in Changchun, China', Environ Sci Pollut Res Int, 25: $17942-49$.

33. Messina, J. P., O. J. Brady, N. Golding, M. U. G. Kraemer, G. R. W. Wint, S. E. Ray, D. M. Pigott, F. M. Shearer, K. Johnson, L. Earl, L. B. Marczak, S. Shirude, N. D. Weaver, M. Gilbert, R. Velayudhan, P. Jones, T. Jaenisch, T. W. Scott, R. C. Reiner, and S. I. Hay. 2019. 'The current and future global distribution and population at risk of dengue', Nature Microbiology, 4: 1508-15.

34. Michelozzi, P., G. Accetta, M. De Sario, D. D'Ippoliti, C. Marino, M. Baccini, A. Biggeri, H. R. Anderson, K. Katsouyanni, F. Ballester, L. Bisanti, E. Cadum, B. Forsberg, F. Forastiere, P. G. Goodman, A. Hojs, U. Kirchmayer, S. Medina, A. Paldy, C. Schindler, J. Sunyer, C. A. Perucci, and Phewe Collaborative Group. 2009. 'High temperature and hospitalizations for cardiovascular and respiratory causes in 12 European cities', Am J Respir Crit Care Med, 179: 383-9.

35. Moghadamnia, M. T., A. Ardalan, A. Mesdaghinia, A. Keshtkar, K. Naddafi, and M. S. Yekaninejad. 2017. 'Ambient temperature and cardiovascular mortality: a systematic review and meta-analysis', PeerJ, 5: e3574.

36. Mourtzoukou, E. G., and M. E. Falagas. 2007. 'Exposure to cold and respiratory tract infections', Int J Tuberc Lung Dis, 11: 938-43.

37. Nelson, E. A., J. S. Tam, L. M. Yu, A. M. Li, P. K. Chan, and R. Y. Sung. 2007. 'Assessing disease burden of respiratory disorders in Hong Kong children with hospital discharge data and linked laboratory data', Hong Kong Med J, 13: 114-21.

38. Onozuka, D. 2015. 'The influence of diurnal temperature range on the incidence of respiratory syncytial virus in Japan', Epidemiol Infect, 143: 813-20.

39. Patz, J. A., D. Campbell-Lendrum, T. Holloway, and J. A. Foley. 2005. 'Impact of regional climate change on human health', Nature, 438: 310-7.

40. Phosri, A., T. Sihabut, and C. Jaikanlaya. 2020. 'Short-term effects of diurnal temperature range on hospital admission in Bangkok, Thailand', Sci Total Environ, 717: 137202.

41. Sun, X., Q. Sun, X. Zhou, X. Li, M. Yang, A. Yu, and F. Geng. 2014. 'Heat wave impact on mortality in Pudong New Area, China in 2013', Sci Total Environ, 493: 789-94. 
42. Tam, W. W., T. W. Wong, S. Y. Chair, and A. H. Wong. 2009. 'Diurnal temperature range and daily cardiovascular mortalities among the elderly in Hong Kong', Arch Environ Occup Health, 64: 202-6.

43. Tjaden, N. B., C. Caminade, C. Beierkuhnlein, and S. M. Thomas. 2018. 'Mosquito-Borne Diseases: Advances in Modelling Climate-Change Impacts', Trends Parasitol, 34: 227-45.

44. Togias, A. G., R. M. Naclerio, D. Proud, J. E. Fish, N. F. Adkinson, Jr., A. Kagey-Sobotka, P. S. Norman, and L. M. Lichtenstein. 1985. 'Nasal challenge with cold, dry air results in release of inflammatory mediators. Possible mast cell involvement', J Clin Invest, 76: 1375-81.

45. Wang, M. Z., S. Zheng, S. L. He, B. Li, H. J. Teng, S. G. Wang, L. Yin, K. Z. Shang, and T. S. Li. 2013. 'The association between diurnal temperature range and emergency room admissions for cardiovascular, respiratory, digestive and genitourinary disease among the elderly: A time series study', Science of the Total Environment, 456: 370-75.

46. Wang, Q., C. Li, Y. Guo, A. G. Barnett, S. Tong, D. Phung, C. Chu, K. Dear, X. Wang, and C. Huang. 2017. 'Environmental ambient temperature and blood pressure in adults: A systematic review and metaanalysis', Sci Total Environ, 575: 276-86.

47. Wang, Z., Y. Zhou, M. Luo, H. Yang, S. Xiao, X. Huang, Y. Ou, Y. Zhang, X. Duan, W. Hu, C. Liao, Y. Zheng, L. Wang, M. Xie, L. Tang, J. Zheng, S. Liu, F. Wu, Z. Deng, H. Tian, J. Peng, X. Wang, N. Zhong, and P. Ran. 2020. 'Association of diurnal temperature range with daily hospitalization for exacerbation of chronic respiratory diseases in 21 cities, China', Respir Res, 21: 251.

48. Watts, N., M. Amann, N. Arnell, S. Ayeb-Karlsson, J. Beagley, K. Belesova, M. Boykoff, P. Byass, W. Cai, D. Campbell-Lendrum, S. Capstick, J. Chambers, S. Coleman, C. Dalin, M. Daly, N. Dasandi, S. Dasgupta, M. Davies, C. Di Napoli, P. Dominguez-Salas, P. Drummond, R. Dubrow, K. L. Ebi, M. Eckelman, P. Ekins, L. E. Escobar, L. Georgeson, S. Golder, D. Grace, H. Graham, P. Haggar, I. Hamilton, S. Hartinger, J. Hess, S. C. Hsu, N. Hughes, S. Jankin Mikhaylov, M. P. Jimenez, I. Kelman, H. Kennard, G. Kiesewetter, P. L. Kinney, T. Kjellstrom, D. Kniveton, P. Lampard, B. Lemke, Y. Liu, Z. Liu, M. Lott, R. Lowe, J. Martinez-Urtaza, M. Maslin, L. McAllister, A. McGushin, C. McMichael, J. Milner, M. MoradiLakeh, K. Morrissey, S. Munzert, K. A. Murray, T. Neville, M. Nilsson, M. O. Sewe, T. Oreszczyn, M. Otto, F. Owfi, O. Pearman, D. Pencheon, R. Quinn, M. Rabbaniha, E. Robinson, J. Rocklov, M. Romanello, J. C. Semenza, J. Sherman, L. Shi, M. Springmann, M. Tabatabaei, J. Taylor, J. Trinanes, J. ShumakeGuillemot, B. Vu, P. Wilkinson, M. Winning, P. Gong, H. Montgomery, and A. Costello. 2021. 'The 2020 report of The Lancet Countdown on health and climate change: responding to converging crises', Lancet, 397: 129-70.

49. Wu, X., Y. Lu, S. Zhou, L. Chen, and B. Xu. 2016. 'Impact of climate change on human infectious diseases: Empirical evidence and human adaptation', Environ Int, 86: 14-23.

50. Yang, J., H. Z. Liu, C. Q. Ou, G. Z. Lin, Q. Zhou, G. C. Shen, P. Y. Chen, and Y. Guo. 2013. 'Global climate change: impact of diurnal temperature range on mortality in Guangzhou, China', Environ Pollut, 175: 131-6.

51. Yang, L. T., Y. M. Chang, T. H. Hsieh, W. H. Hou, and C. Y. Li. 2018. 'Associations of Ambient Temperature with Mortality Rates of Cardiovascular and Respiratory Diseases in Taiwan: A 
Subtropical Country', Acta Cardiol Sin, 34: 166-74.

52. Zhang, F., H. Zhang, C. Wu, M. Zhang, H. Feng, D. Li, and W. Zhu. 2021. 'Acute effects of ambient air pollution on clinic visits of college students for upper respiratory tract infection in Wuhan, China', Environ Sci Pollut Res Int.

53. Zhang, Y., C. Li, R. Feng, Y. Zhu, K. Wu, X. Tan, and L. Ma. 2016. 'The Short-Term Effect of Ambient Temperature on Mortality in Wuhan, China: A Time-Series Study Using a Distributed Lag Non-Linear Model', Int J Environ Res Public Health, 13.

54. Zhang, Y., C. Yu, J. Bao, and X. Li. 2017. 'Impact of temperature variation on mortality: An observational study from 12 counties across Hubei Province in China', Sci Total Environ, 587-588: 196-203.

55. Zhang, Y., C. Yu, and L. Wang. 2017. 'Temperature exposure during pregnancy and birth outcomes: An updated systematic review of epidemiological evidence', Environ Pollut, 225: 700-12.

56. Zhang, Y., C. Yu, J. Yang, L. Zhang, and F. Cui. 2017. 'Diurnal Temperature Range in Relation to Daily Mortality and Years of Life Lost in Wuhan, China', Int J Environ Res Public Health, 14.

57. Zhao, D., X. Zhang, Z. Xu, J. Cheng, M. Xie, H. Zhang, S. Wang, K. Li, H. Yang, L. Wen, X. Wang, and H. Su. 2017. 'Impact of short-term temperature variability on emergency hospital admissions for schizophrenia stratified by season of birth', Int J Biometeorol, 61: 589-99.

58. Zhao, Y., Z. Huang, S. Wang, J. Hu, J. Xiao, X. Li, T. Liu, W. Zeng, L. Guo, Q. Du, and W. Ma. 2019. 'Morbidity burden of respiratory diseases attributable to ambient temperature: a case study in a subtropical city in China', Environ Health, 18: 89.

59. Zheng, S., M. Wang, B. Li, S. Wang, S. He, L. Yin, K. Shang, and T. Li. 2016. 'Gender, Age and Season as Modifiers of the Effects of Diurnal Temperature Range on Emergency Room Admissions for Cause-Specific Cardiovascular Disease among the Elderly in Beijing', Int J Environ Res Public Health, 13.

60. Zhou, X., A. Zhao, X. Meng, R. Chen, X. Kuang, X. Duan, and H. Kan. 2014. 'Acute effects of diurnal temperature range on mortality in 8 Chinese cities', Sci Total Environ, 493: 92-7.

\section{Figures}




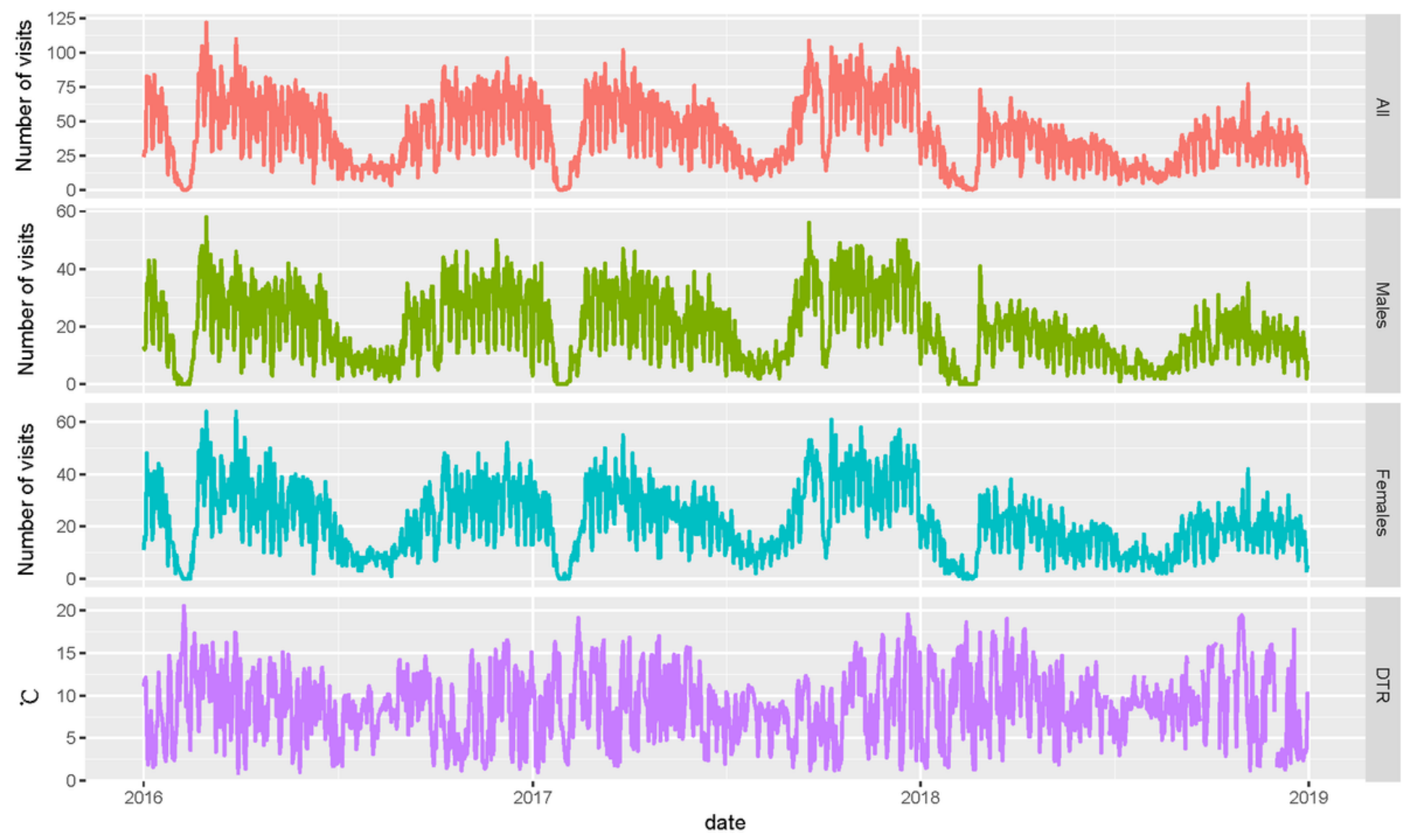

Figure 1

The descripts of daily outpatient visits for UTRI and DTR from 2016 to 2018 in hospital of Wuhan University, China. 


$$
\begin{aligned}
& \text { 돔 을 } \\
& \text { Relh } 1-0.07-0.45-0.51-0.4-0.42-0.11-0.14 \\
& \text { Tmp } \mathbf{- 0 . 0 7} \\
& 0.62-0.01-0.26-0.4-0.44-0.57
\end{aligned}
$$

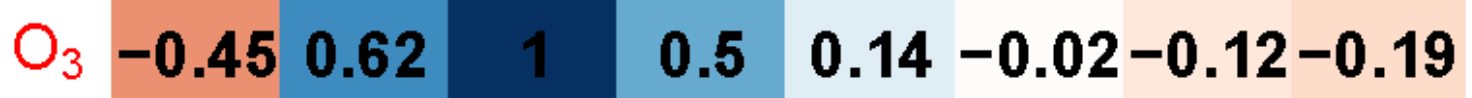

$$
\begin{aligned}
& \text { DTR }-0.51-0.01 \quad 0.5 \\
& \begin{array}{llll}
0.53 & 0.47 & 0.46 & 0.27
\end{array} \\
& \begin{array}{lllllllll}
\mathrm{PM}_{10} & -0.4 & -0.26 & 0.14 & 0.53 & 1 & 0.65 & 0.71 & 0.8
\end{array}
\end{aligned}
$$

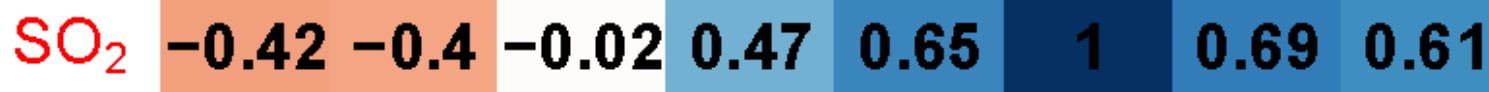

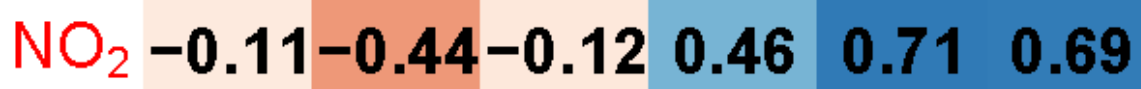

$$
\begin{aligned}
& 0.67 \\
& \begin{array}{llllll}
\mathrm{PM}_{2.5} & -\mathbf{0} .14-0.57-0.19 & 0.27 & 0.8 & 0.61 & 0.67
\end{array}
\end{aligned}
$$

Figure 2

The spearman correlation coefficient between environmental factors. DTR: diurnal temperature range, Tmp: temperature, $\mathrm{RH}$ : relative humidity 
(A) All

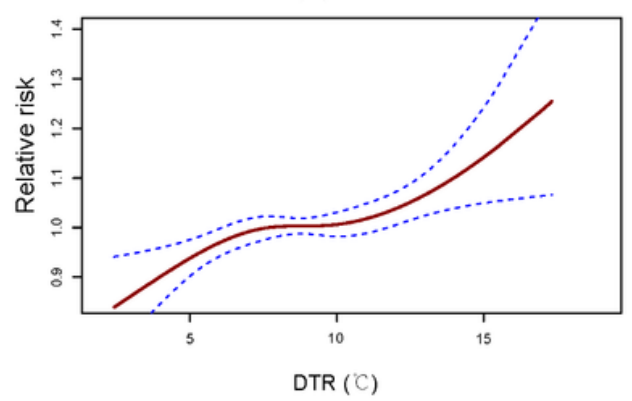

(B) Males

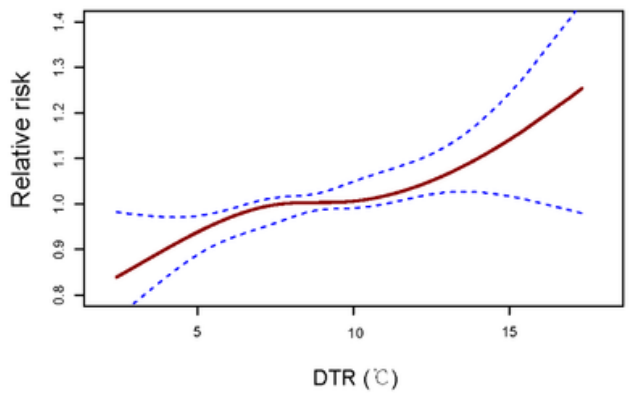

(C) Females

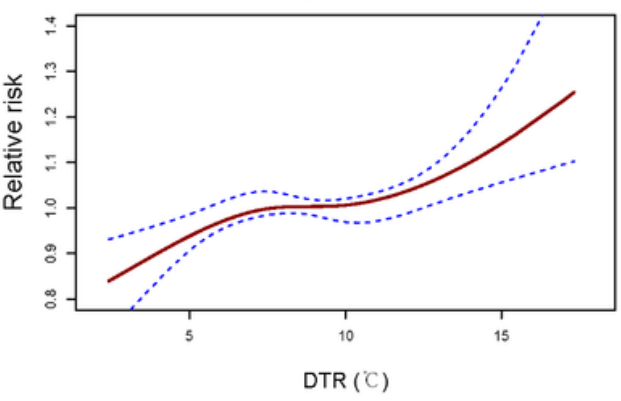

Figure 3

The exposure-response curves between clinic visits of URTI and DTR at lag 06 days.
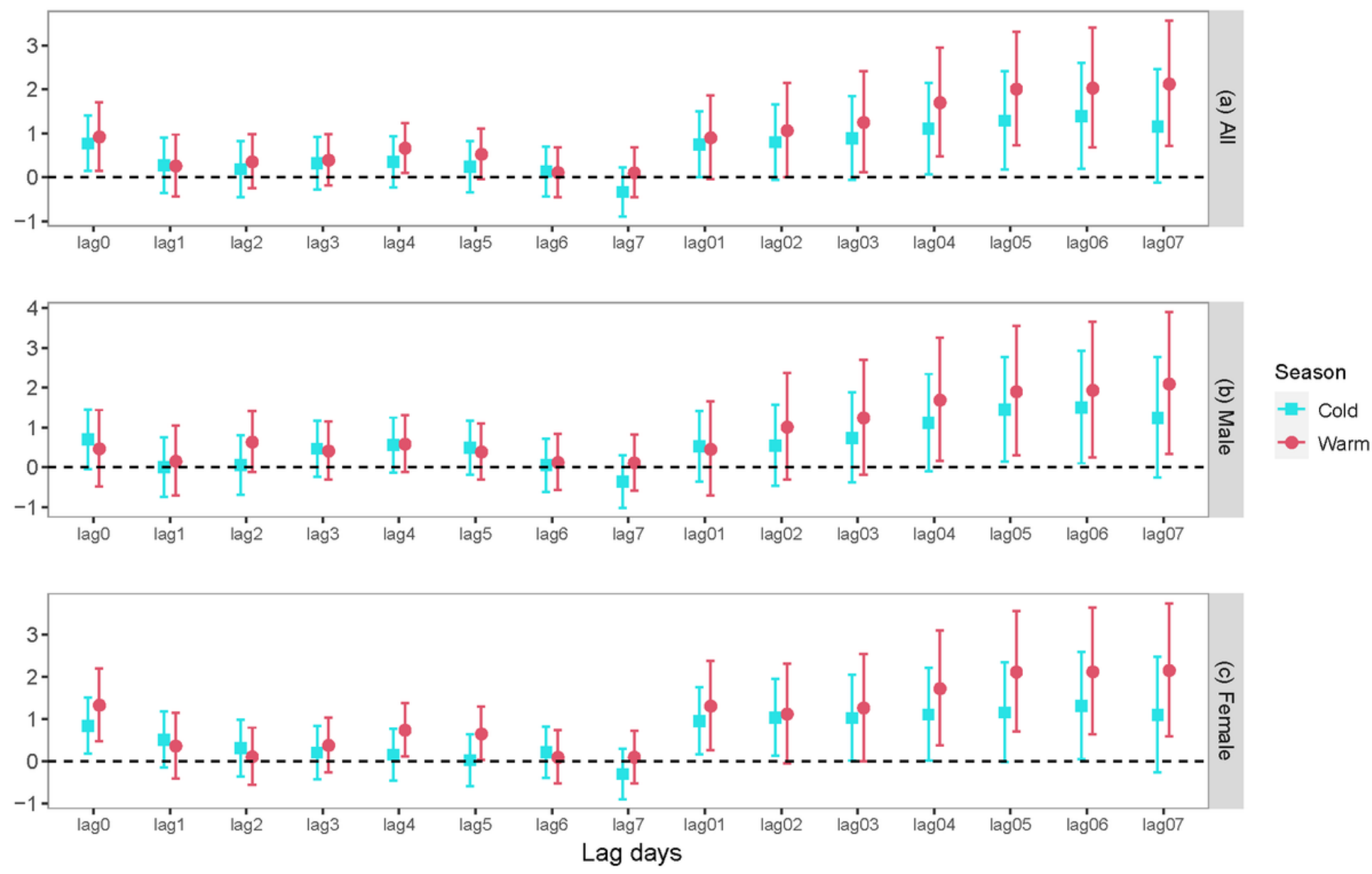

Figure 4

Percent changes and $95 \% \mathrm{Cl}$ for URTI clinic visits of college students associated with per $1^{\circ} \mathrm{C}$ increase in DTR stratified by season at different lag days.

\section{Supplementary Files}

This is a list of supplementary files associated with this preprint. Click to download. 
- SupplementaryMaterial.docx

Page 22/22 